\title{
Creation of a Device for Testing of the Rock Samples for Gap in Volumetric Compression Chamber
}

\author{
Svetlana Kostyuk ${ }^{1}$, Nikolay Bedarev ${ }^{2}$, Oleg Lyubimov ${ }^{3, *}$, and Yunliang Tan ${ }^{4}$ \\ ${ }^{1}$ T.F. Gorbachev Kuzbass State Technical University, the Administration, 650000 Kemerovo, 28 \\ Vesennya st., Russian Federation \\ ${ }^{2}$ T.F. Gorbachev Kuzbass State Technical University, Prokopyevsk branch, Department of technology \\ and complex mechanization of mining, 653033 Prokopyevsk, 19 Nogradskaya st., Russian Federation \\ ${ }^{3}$ T.F. Gorbachev Kuzbass State Technical University, Department of information and automated \\ manufacturing systems, 650000 Kemerovo, 28 Vesennya st., Russian Federation \\ ${ }^{4}$ Shandong University of Science and Technology, Qingdao, China
}

\begin{abstract}
A device for the volume compression chamber of the samples is described and some possibilities for testing the samples are presented: compressive strength, angle of internal friction, and adhesion values of coal and host rocks. In addition, descriptions of patents for devices allowing to test rocks for breaking during volume compression are given.
\end{abstract}

\section{Introduction}

Currently, in addition to indicators of the strength of rocks for uniaxial compressiontension, there is a need to expand the indicators of physical and mechanical properties of rocks [1]. For these purposes, in the conditions of mining enterprises (and for training purposes - in the Prokopyevsky branch of KuzGTU), the Azimuth 85D01B volumetric compression chamber is actively used as one of the most common modifications. And with the help of the BV-21 chamber, which is no less common in the mining industry, it is possible to obtain data allowing, for example, to predict the stability of shaft shafts in terms of ultimate strength $\left(\sigma_{\text {compr.lim }}\right)$, and in terms of long-term strength $\left(\sigma_{\text {compr.res }}\right)$ - pressure on lining of capital workings, according to pre-limiting and transcendental characteristics of rocks - the tendency of rocks to rock blows.

It should be borne in mind that the need to test samples of coal and rocks is also due to the fact that currently, usually when calculating displacements of the mine workings, bearing abilities of pillars, supports, etc., the strength characteristics of a coal-bearing mass are borrowed, as a rule, from exploration data batches issued at the stage of exploration, for cores drilled from an array in a natural state, not affected by mining.

However, the fact is known that when conducting mining operations, the natural humidity and stress state of the massif dramatically change, mainly towards a significant decrease in

\footnotetext{
*Corresponding author: oleglyub@gmail.com
} 
the resistance of rock layers. Significantly reduced the strength characteristics of rocks near zones of geological disturbances and in zones of influence from treatment.

\section{Theory of the question}

The sources of information abroad [2,3] describe the modeling of the state of the rock mass taking into account simulation of strength characteristics similar to specific field conditions, and the process of formation of pressure zones in front of the face of the complex is studied. In addition, foreign authors $[4,5]$, in relation to local field conditions, also studied the length of the pressure support zones, and in $[6,7]$, the roof lowering in conveyor and ventilation drifts was studied. In $[8,9]$, the difficulty of solving the problem of efficient and safe development of reserves without taking into account the influence of geological and mining factors is noted.

As mentioned above, in the branch of KuzGTU in Prokopyevsk, taking into account the state standard specifications for rock testing, the methods described in [1] are actively used and there is the necessary special equipment for this. Using the Azimuth $85 \mathrm{D} 01 \mathrm{~B}$, it seems possible to build passports of bulk strength of rocks taking into account the depth of mining operations, with the construction of several Mora circles and their envelopes. The disadvantage of these chambers is the lack of the ability to test rocks for breaking when simulating the depth of the rocks. As for the BV-21 camera and similar foreign and domestic cameras [10-13], this possibility cannot be realized due to the small volume of the cameras of extreme deformation, since they were created only for placing samples $(d=42$ $\mathrm{mm}, \mathrm{h}=84 \mathrm{~mm}$ ) but in the Azimuth 85D01B chamber this possibility can be realized, since in this chamber in a special bucket it is possible to place samples for testing $(\mathrm{d}=100 \mathrm{~mm}, \mathrm{~h}$ $=200 \mathrm{~mm}$ ). Therefore, the authors decided to develop a device that fits in a bucket for fixing samples and lowering them into the 85D01 Azimut volumetric compression chamber.

\section{Materials and methods}

As indicated above, to solve the problem, the Azimut 85D01 volumetric compression chamber [1], the main structural elements of which are shown in Fig. 1, was adopted as the basic design. 1.

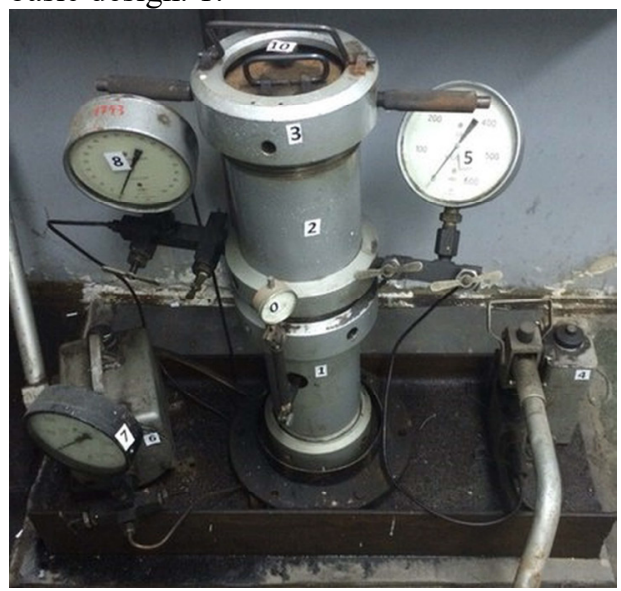

a

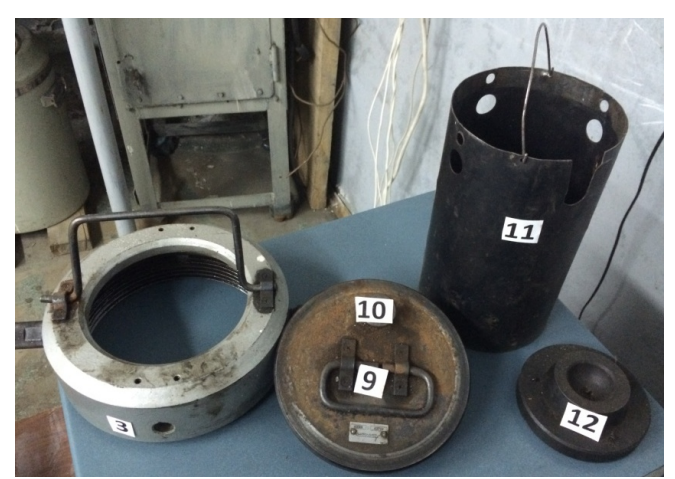

b

Fig. 1. Volumetric compression chamber Azimuth 85D01B: a - the lower part; b - the upper part. 
According to fig. 1, the enlarged volume compression chamber consists of the upper and lower parts. In the lower part of the structure (fig. 1, a): 1 - lower cylinder (inner diameter $146 \mathrm{~mm}$ ); 2 - the upper cylinder of the same diameter; 3 - removable ring for fixing the cover of the upper cylinder; 4 - pump for loading the sample along the axis until the sample is destroyed; 5 - pressure gauge for measuring the magnitude of the pressure developed by the pump when supplied to the lower cylinder; 6 - pump for supplying lateral pressure and maintaining its set value with an error of $\pm 5 \%, 7$ - pump pressure gauge $6 ; 8$ pressure gauge for controlling lateral oil pressure (constant load during the test is provided by continuous manual control).

In the upper part of the structure (fig. 1, b): 9 - a cover on the top of the chamber with an air outlet; 10 - plug for opening the hole and exhausting air from the upper chamber; 11 a bucket for installing the test sample and storing the remains of the rock after the destruction of the sample (diameter of the bucket $137 \mathrm{~mm}$, height $260 \mathrm{~mm}$ - based on the maximum possible placement of samples $100 \times 200 \mathrm{~mm}$ ); 12 - plate mounted on the sample; 13 - ball joint $d=40 \mathrm{~mm}$ for uniform load transfer to the plate $9 ; 14$ - rock sample $d=50 \ldots$ $100 \mathrm{~mm}, \mathrm{~h}=100-200 \mathrm{~mm} ; 15$ - piston-pusher for loading sample 14 along the axis to failure; 0 - dial gauge, fixing the movement of the piston-pusher 15 together with the sample 14 until its destruction.

For the manufacture of samples for the chamber of volume compression $(d=50 \ldots 100$ $\mathrm{mm})$ and the chamber of extreme deformation $(\mathrm{d}=42 \ldots 44 \mathrm{~mm})$, special devices are available in the laboratory.

The disadvantage of this stabilometer is the impossibility of testing the samples for rupture when setting the side pressure. The indicated drawback is eliminated in the stabilometer improved by the authors [14]. The developed technical solution is illustrated by drawings, where fig. 2 , it shows a cross-section of a stabilometer with the specimen installed for testing, and fig., $2 \mathrm{~b}$ shows the assembly of the specimen prepared for tensile testing before installation in a bucket of a stabilometer.

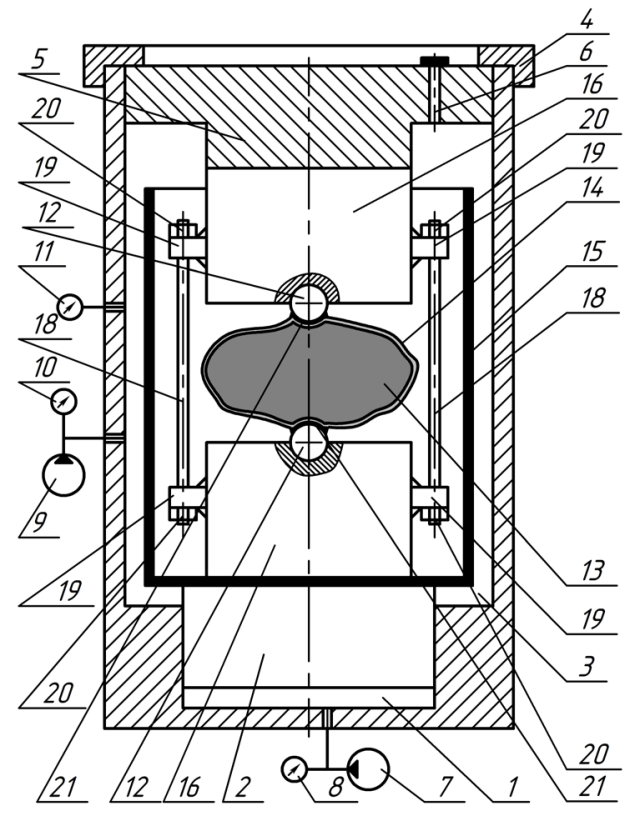

a

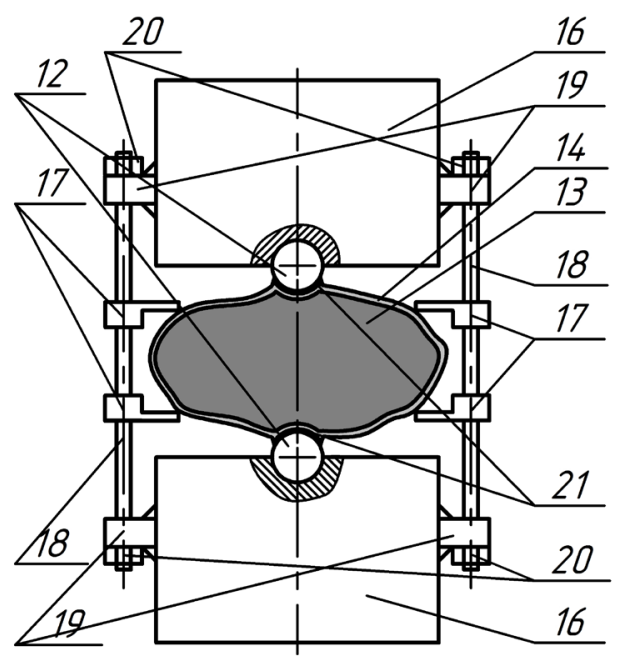

b

Fig. 2. The proposed design of the stabilometer: a - cross-section of the stabilometer with the specimen installed for testing; $b$ - assembly of the specimen prepared for tensile testing. 
The stabilometer (Fig. 1, a) contains a working cylinder 1 with a piston 2 and a working chamber 3, a cover 5 fixed by a removable ring 4, a cover 5 of the working chamber 3 with a blocked opening 6 , a pump 7 with a pressure gauge 8 for creating and monitoring axial pressure, a pump 9 with a pressure gauge 10 for supplying and controlling lateral pressure, a pressure gauge 11 for controlling lateral pressure in the working chamber 3, which is under the influence of counter indenters 12 , the test specimen 13 , covered with waterproofing material 14 , a device for monitoring the values of deformation of the sample (is not shown in the illustration), a bucket 15 for installing the specimen 13 and collecting products of its destruction.

In preparation for the tensile tests (fig. 2), the specimen 13, before being installed in the bucket 15 , was held by oncoming indenters 12 in the holes of the additional support legs 16 with the help of the folding platforms 17 on the guide rods 18 , which were axially moved through the lugs 19 on the additional support legs 16 and fixed on the ends with nuts 20 .

The surface of the indenters 12 in contact with the specimen 13 is covered with glue 21 .

The proposed technical solution works as follows.

Rock samples proposed for testing are drilled or otherwise extracted directly in the faces.

Therefore, in the most general case, the shape of specimen 13 is arbitrary.

A necessary step in preparing specimen 13 for testing is to coat it with waterproofing material 14 (for example, with a rubber film), which prevents oil from entering the pores of specimen 13.

In the case of tensile tests before installation in a bucket 15 (fig. 2, b), specimen 13 is preliminarily prepared in such a way that it is retained by oncoming indenters 12 in the holes of additional supporting supports 16 , the total height of which allows the height of the specimen 13 , tested for breaking, to be taken up to the height standard samples tested for compression. Guaranteed retention of the specimen 13 of arbitrary shape in the assembly is carried out using the folding pads 17 located on the guide rods 18 . The guide rods 18 are skipped with the possibility of axial movement through the lugs 19 on additional load-bearing supports 16 . By fixing the guide rods 18 at the ends with nuts 20, a variety of fasteners for the threaded connection, the integrity of the assembly of the sample with mating parts is ensured, accompanied, if necessary, by the possibility of quick temporary disassembly and regulation.

When installing the prepared specimen 13 in the bucket 15 in the above manner, the pads 17 recline and subsequently do not interfere with the tests. At the same time, the guide rods 18 remain in the assembly (fig. 1, a).

Next, the working chamber 3 is covered with a cover 5 and fixed with a removable ring 4. The oil is slowly injected under the piston 2 of the working cylinder 1 by the pump 7 under pressure controlled by a pressure gauge 8, until the additional support bearings 16 come in contact with the cover 5 with the hole 6 not covered. After that, the cover 5 is finally fixed in the working position.

Then, with the hole 6 not covered, the working chamber 3 is pumped under pressure by a pump 9 under pressure controlled by a pressure gauge 10, after which the hole 6 is closed.

Specimen 13 is loaded with lateral pressure to a predetermined value (under the control of pressure gauge 11). Then the sample 13 is loaded by axial pressure until fracture. This ensures the release from the working chamber 3 of oil displaced by the rising piston 2 of the working cylinder 1 to maintain a constant value of lateral pressure.

To prevent damage to the waterproofing material 14 covering the specimen 13 during the tensile test, the surface of the indenters 12 in contact with the specimen 13 is covered with glue 21 .

The pressure of the oil in the working cylinder according to the manometer 8 with the support of the load-bearing support 16 in the cover 5 increases, which indicates the axial loading of the specimen 13. The conducted tensile tests are facilitated by the fact that the additional load-bearing supports 16 with the counter indenters 12 approach each other, acting on the specimen 13 , exclusively along the guide rods 18 , which were axially moved through the lugs 19, without the negative influence of the specified side pressure. 
A sharp decrease in the pressure gauge 8 indicates the destruction of specimen 13. In this case, a jump in the readings of the device for monitoring the strain values of the sample (not shown in the illustrations) occurs.

The disadvantage of this device is the low efficiency at high time costs for preparing for testing in a tensile tester due to the fact that:

1) load-bearing supports having holes for installing spherical indenters do not allow tensile testing of rock samples using wedge indenters;

2) load-bearing supports are heavy, which complicates the installation of the device assembly with the sample for testing in a stabilometer;

3 ) it takes time to move the piston of the working cylinder of the stabilometer immediately before testing in order to compensate for the changing thickness of the samples in the batch.

A new version of the solution proposed by the authors of [15] is illustrated by the drawing, where fig. 3 shows the complete assembly with a sample prepared for testing before installation in a stabilometer.
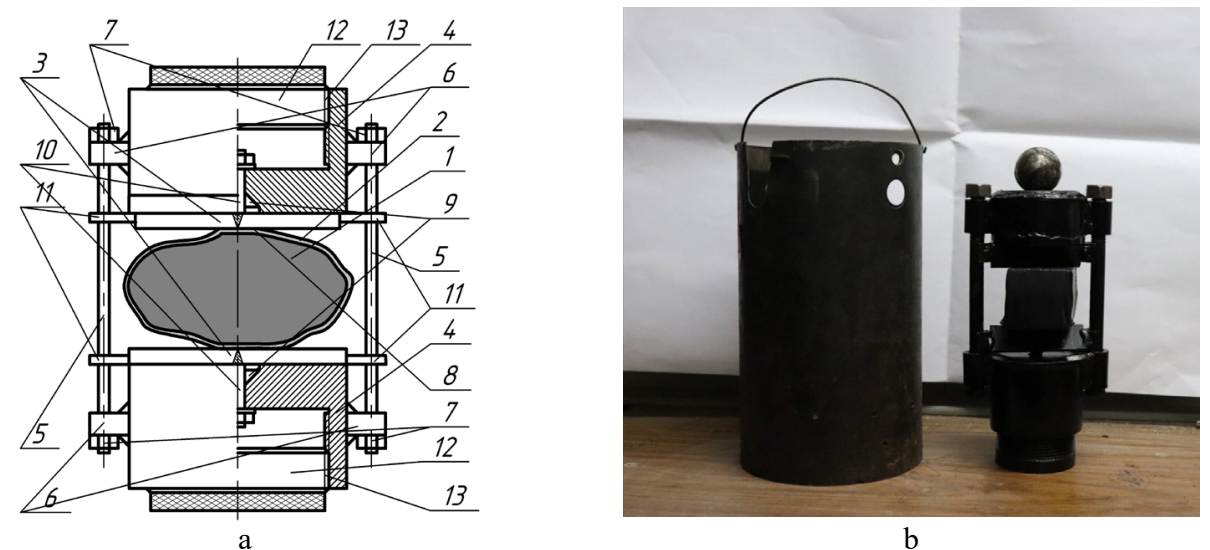

Fig. 3. The device for fixing the specimen when tested in a stabilometer: $a$ - the assembly device; $b$ the material analogue.

The device for fixing the specimen when tested in a stabilometer contains a specimen 1, covered with a waterproofing material 2 and held by counter indenters 3 in the holes of the additional load-bearing supports 4 by means of guide rods 5, passed through the lugs 6 on the additional load-bearing supports 4 and fixed on the ends by nuts 7 . The surface of the indenters 3 in contact with the specimen 1 is coated with glue 8 .

In preparation for tensile tests, the additional load-bearing supports 4 are hollow, the inner ends of each of them are provided with holes 9 for a fixed installation of the rods 10 with wedge shaped indenters 3 moving along the guide rods 5 in the presence of auxiliary lugs 11 at their ends, the outer ends of each of they are equipped with covers 12 , moving to a predetermined height along the thread 13 .

The proposed technical solution works as follows.

Rock specimens proposed for testing are drilled or otherwise extracted directly in the faces.

In the most general case, the thickness of specimen 1 varies over a wide range. Specimen 1 prepared for testing is coated with a waterproofing material 2 (for example, with a rubber film), which prevents oil from entering its pores.

When preparing tensile tests before installation in a stabilometer, sample 1 is preliminarily prepared in such a way that it is retained by oncoming indenters 3 on additional load-bearing supports 4 . When using counter indenters 3 of a wedge shape, the rods 10 present on them are installed in the holes 9 on the inner ends of each of the additional load-bearing supports 4 . The rods 10 are fixed inside the hollow additional loadbearing supports 4 , for example, by a threaded connection or lock washers. 
When assembling the device, due to the movable mating of the auxiliary eyes 11 at the ends of the indenters 3 of the wedge shape and guide rods 5, passed through the lugs 6 on the additional load-bearing supports 4 , movement along them with a combination of wedge blades is ensured and, therefore, ensuring oncoming and coaxial movement indenters 3 wedge shaped indenters during subsequent tensile tests. By fixing the guide rods 5 at the ends with nuts 7, the integrity of the assembly of sample 1 with associated parts is ensured.

Due to the covers 12, the outer ends of each of the additional support legs 4 are covered from the outside, while it is also possible to move the covers to a predetermined height along the thread 13 to compensate for the changing height of the specimens in the batch.

To prevent damage to the waterproofing material 2 covering the sample 1 during the tensile test, the surface of the indenters 3 at the contact with the specimen 1 is covered with glue 8 .

Based on the foregoing, a material analogue was manufactured and tested. Fig. 2, b shows a bucket next to the proposed device, which, with the specimen fixed in it, will be placed in it, and then in the stabilometer.

\section{Conclusion}

The cited patents for devices [14, 15] illustrate the fact that the idea of adapting a wellknown device to the solution of specific tasks made it possible to ultimately create and test a real material final design of a device for fixing samples for placement in a volume compression chamber for testing mountain samples rocks of various configurations to break when simulating a given depth.

There is the prospect of creating new adaptive devices with the possibility of compression tests for various rocks in order to obtain refined dependences and physicomechanical characteristics, new passports of bulk strength of rocks.

\section{References}

1. S. Kostyuk, N. Bedarev, Research of Strength Characteristics of Rocks (KuzsTU, Kemerovo, 2015)

2. V. Sotskov, I. Saleev, Min. of min. depos., 12, 23 (2013)

3. V. Sotskov, O. Gusev, Progr. Techn. of coal, 67, 11 (2014)

4. K. D. Erer, A. Heidarieh-Zadeh, Min. Sc. and Techn., 2, 3 (1985)

5. P. H. Lane, Rept. Invest. Bur. Mines us Dep. Intez, 89 (1985)

6. L. Fu-chen, Zh. Wei, S. Ai-hua, The El. J. of Geotech. Eng., 18 (2013)

7. P. Peng-Zhi, J. Rutqvist, F. Xia-Ting, Y. Fei, J. Quan, Rock Mech. and Rock Eng., 47, $6(2014)$

8. J. L. Luo, Unpublished Thesis (West Virginia University, Parkersberg, 1997)

9. C. Mark, Multiple-seam longwall mining in the United States: lessons for ground control (NIOSH, Pittsburgh, 2007)

10. Pat. 1998722 of USA (1935)

11. Pat. 39480 of Ukraine (2009)

12. Pat. 2359125 of Russian Federation (2009)

13. Pat. 2616946 of Russian Federation (2017)

14. Pat. 184648 of Russian Federation (2018)

15. Pat. 193857 of Russian Federation (2019) 